for maintaining sphygmomanometers and for instructing users in the correct method of operation.

${ }^{1}$ Mishra, S C, et al, fournal of Medical Engineering and Technology, 1977, 1, 159.

2 Simpson, J A, et al, American Heart fournal, 1965, 70, 208.

3 Silverberg, D S, Shemesh, E, and Iaina, A, British Medical fournal, $1977,2,1331$.

${ }^{4}$ Rose, G A, Holland, W W, and Crowley, E A, Lancet, 1964, 1, 296.

5 Conceicao, S, Ward, M K, and Kerr, D N S, British Medical fournal, $1976,1,886$.

(Accepted 5 February 1979)

Department of Clinical Physics and Bio-Engineering, West of Scotland Health Boards, Glasgow G4 9LF

A SHAW, BSC, MIMECHE, principal physicist

C DEEHAN, BSC, senior physicist

J M A LENIHAN, OBE, FRSED, director

\section{Two patients with schizophrenic-like psychosis after treatment with beta-adrenergic blockers}

We have recently seen two patients suffering from psychotic illnesses which developed during treatment with $\beta$-adrenergic-blocking drugs that had been prescribed for cardiovascular illnesses.

\section{Case 1}

This 53-year-old woman's sister, son, and cousin suffered from schizophrenia. She had no psychiatric history, although she had always been suspicious of people. She had been taking $\beta$-adrenergic-blocking drugs for angina for several months, and three weeks before admission the dose of propranolol hydrochloride had been increased to $40 \mathrm{mg}$ three times a day. Since then she had gradually become more psychotic with delusions that there were "mental breakdowns" and "abuse" from the occupants of a house near where she lived, and she spent much time looking for the house. She also believed that her telephone calls were being intercepted and repeatedly referred to "the north London conspiracy." She had auditory hallucinations, claiming that two or three voices were talking together about her and making a running commentary on her behaviour. Immediately before admission she had been wandering all over London and had not slept for a week or eaten for three days; the propranolol had then been withdrawn by her GP. On admission trifluoperazine and haloperidol were substituted. She returned home against medical advice after two days in hospital. Since discharge she has taken no neuroleptic medication and has remained well for three months, with no psychotic symptoms.

\section{Case 2}

This 66-year-old woman had no family or personal history of psychiatric illness. She had been treated for two years with oxprenolol hydrochloride $80 \mathrm{mg}$ three times a day, but nine months before referral the dose had been increased to $160 \mathrm{mg}$ thrice daily. She had gradually become withdrawn and began to suffer from delusions and hallucinations. She believed that the people next door were plotting against her, could see into her room, and had placed an electrical gadget in the wall to watch her and read her thoughts. She heard voices repeating her thoughts out loud and commenting on her actions. Before her illness she had been on good terms with her neighbours; and the condition came to light one evening when she started screaming at the window that she was being burgled and the police were called. Under outpatient supervision her dose of oxprenolol hydrochloride was reduced to $80 \mathrm{mg}$ three times a day and treatment was started with $10 \mathrm{mg}$ of trifluoperazine and $50 \mathrm{mg}$ of orphenadrine thrice daily. Her mental state improved rapidly and after one week she was free from all her psychotic symptoms and remained well at one month's follow-up.

\section{Comment}

Depression and delirium are well-known side effects of betablockers, ${ }^{1}$ and visual hallucinations have also occurred. The auditory hallucinations experienced by both these patients were first-rank Schneiderian schizophrenic symptoms. Both patients were undoubtedly suffering from a schizophrenic-like illness rather than a toxic confusion state. The relationship between their psychoses and their treatment with beta-blockers may have been a chance one, as both schizophrenia and treatment with beta-blockers are common. Nevertheless, in each case the onset of psychotic symptoms dated from the increase in dose of the drugs, and recovery was quick and complete when the dose was reduced; the first patient recovered with very little neuroleptic medication.

Whether beta-blockers have a central action is uncertain, and their effect in treating anxiety is probably mediated through the cardiovascular system. ${ }^{2}$ Biochemical and neuropharmacological studies in animals have provided convincing evidence of the existence of central $\beta$-adrenoceptors, and antagonists have been shown to act on them in animals. ${ }^{3}$ In man electrocardiographical changes have been shown in chronic schizophrenic patients taking increasing doses of propranolol, ${ }^{4}$ and the double-blind trial of Yorkston et al clearly showed that propranolol was an effective treatment for patients with schizophrenia who had not improved on neuroleptic medication. ${ }^{5}$ The effect of the beta-blockers on these two patients therefore seems to be paradoxical. The role of beta-blockers in the mechanism of schizophrenia is clearly complex and requires further investigation.

We thank Dr M Honey, Dr S Allan, Professor R G Priest, and Dr R Brosnan for their help.

${ }^{1}$ Stephens, S A, American fournal of Cardiology, 1966, 18, 463.

${ }^{2}$ Lancet, 1976, 2, 611.

${ }^{3}$ Conway, J, et al, Clinical Science and Molecular Medicine, 1978, 54, 18.

${ }^{4}$ Orzack, M H, and Branconnier, R, Psychopharmacologia, 1973, 29, 299.

5 Yorkston, N J, et al, Lancet, 1977, 2, 575.

(Accepted 7 February 1979)

St Bernard's Hospital, Southall, Middlesex

J STEINERT, MB, FRCPSYCH, consultant psychiatrist

C R PUGH, MB, MRCPSYCH, clinical research assistant

\section{Serum ferritin concentration and oral iron treatment in patients on regular haemodialysis}

Iron deficiency contributes to the anaemia of some patients receiving maintenance haemodialysis. Oral iron can both prevent and correct iron deficiency anaemia and marrow iron depletion in such patients, ${ }^{12}$ and continuous oral iron is, therefore, commonly prescribed. Iron overload is generally assumed to be unlikely with oral-as distinct from parenteral-iron, but this has been little studied and the usual dose required to maintain haemodialysis patients in iron balance has not been established. We have used serum ferritin concentration as an index of iron state and here report observations in three groups of patients undergoing haemodialysis and taking different amounts of oral iron.

\section{Patients, methods, and results}

Sixty-one patients ( 36 men) were studied. All but one patient underwent dialysis for two 10- or 11-hour periods or three 5- to 8-hour periods per week using standard Kiil or Multipoint dialysers (Meltec Ltd). The single exception underwent dialysis for three 6-hour periods weekly using an X23 coil dialyser (Extracorporeal). Membranes used, other dialysis techniques, diet, and supplements have been described. ${ }^{1}$ Patients had received dialysis for two months to 12 years (mean 42 months; 17 for less than 12 months). Twenty-seven patients had received blood transfusions. The mean transfusion rate for all 61 patients was $0 \cdot 16$ units/month. Only three patients had received intravenous iron at any time and more had received it within a year of starting the study. Great economy was exercised in blood sampling for routine investigation. This accounted for blood loss of 5 to $15 \mathrm{ml}$ a month. On starting haemodialysis patients were prescribed ferrous sulphate $200 \mathrm{mg}$ thrice daily (equivalent to $180 \mathrm{mg}$ elemental iron daily) for one month, and those who tolerated this were then prescribed $400 \mathrm{mg}$ thrice daily $(360 \mathrm{mg}$ elemental iron daily). A few patients were transferred to other preparations if intolerant to ferrous sulphate. Many had received oral iron before haemodialysis. Actual-as opposed to prescribed-daily iron intake was assessed by detailed and sympathetic questioning by two of us (AMC and JNF). Blood 
for serum ferritin estimation was taken either before dialysis or on a nondialysis day into iron-free containers, and serum was stored at $-20^{\circ} \mathrm{C}$ until assayed. Haemoglobin concentration was measured simultaneously. Serum aspartate transaminase concentration measured by autoanalyser in all patients ranged from four to $57 \mathrm{IU} / 1$; in only three patients did the concentration exceed $50 \mathrm{IU} / 1$. Serum ferritin concentration was measured by radioimmunoassay on all samples as a single batch. ${ }^{3}$ The normal range using this method is $15-250 \mu \mathrm{g} / \mathrm{l}$. Serum ferritin concentration is normally distributed on a logarithmic scale. Statistical analysis by Student's $t$ test was therefore performed on logarithms, and geometric means are quoted.

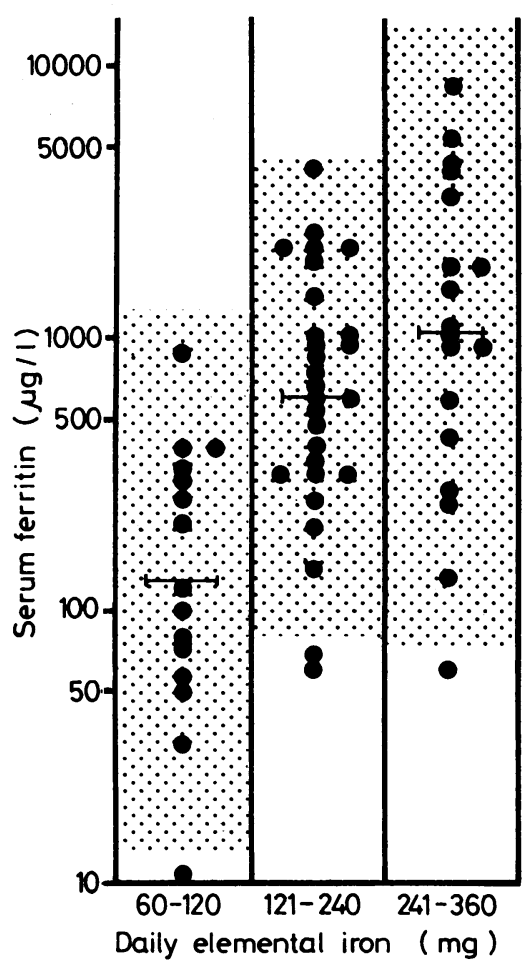

Mean serum ferritin concentrations after low, intermediate, and high intakes of elemental iron. Shaded areas indicate $95 \%$ confidence limits.

Mean serum ferritin concentration was $493 \mu \mathrm{g} / \mathrm{l}$ (range 10-8600 $\mu \mathrm{g} / \mathrm{l}$ ). Serum ferritin was raised in 44 patients and normal in 16 patients; only in the patient using an X23 coil dialyser was the value subnormal. There was no significant correlation between haemoglobin and serum ferritin concentrations. There was no significant difference in serum ferritin concentration between patients haemodialysed for less than 12 months and the remainder, between transfused and non-transfused patients, between men and women, between menstruating and non-menstruating women, or between the nine patients with polycystic kidneys and the remainder. There was no significant correlation between total amount of oral iron received since starting haemodialysis and serum ferritin concentration. Patients were divided into three groups according to average daily intake of elemental iron since starting haemodialysis or in the 12 months preceding the study in the case of patients dialysed for more than a year. No patient admitted to taking less than $60 \mathrm{mg}$ elemental iron daily. A low-intake group (15 patients) ingested $60-120 \mathrm{mg}$ daily, an intermediate group (28) ingested $121-240 \mathrm{mg}$ daily, and a high intake group (18) ingested 241-360 mg daily. Significant differences in mean serum ferritin concentration were found between the low-intake and the other two groups $(\mathrm{P}<0.001$ in each case; see figure).

\section{Comment}

We measured serum ferritin to assess iron state since it correlates well with the state of marrow iron stores in patients treated with haemodialysis. ${ }^{4}$ Our results indicate that most patients were receiving unnecessarily large amounts of oral iron. While there is no proof that any harm has resulted from excessive iron ingestion, it would seem wise to avoid overtreatment on grounds of possible risk, patient convenience, and economy. It is unnecessary to exceed $120 \mathrm{mg}$ elemental iron daily as maintenance treatment in patients treated as described by flat-board haemodialysis. This dose is too large in some patients. An adequate maintenance dose for most patients is probably $60 \mathrm{mg}$ elemental iron (one ferrous sulphate tablet) daily.

Dialysis carried out as described is associated with the loss of about
$20 \mathrm{ml}$ blood in dialysis membranes and lines per dialysis and with a mean percentage daily loss of iron ranging from 0.02 to $1.3 \% .^{5}$ Our conclusions are therefore applicable only to patients undergoing haemodialysis whose iron losses are similar to this. The single patient with a low serum ferritin concentration had both used a coil dialyser and taken only $60 \mathrm{mg}$ of elemental iron daily for three years before the study and also menstruated regularly. Iron requirements in patients using coil dialysers need further investigation.

These observations relate to maintenance treatment. Many patients starting haemodialysis who have not had iron supplementation are iron depleted. ${ }^{1}$ In such patients higher doses of oral iron may be required initially.

We thank the patients and staff of the regional renal unit, St Bartholomew's/ St Leonard's Hospital, for their co-operation and Dr J Allawi, Miss $\mathbf{R}$ Minchinton, Professor D L Mollin, Mrs J Jessop, and Mrs J Wadsworth for their help.

Requests for reprints should be addressed to Dr L R I Baker.

${ }^{1}$ Baker, L R I, et al, Clinical Science and Molecular Medicine, 1975, 48, 429.

2 Gokal, R, et al, Quarterly fournal of Medicine. In press.

3 Barnett, M D, et al, fournal of Clinical Pathology, 1978, 31, 742.

${ }^{4}$ Hussein, S, et al, British Medical fournal, 1975, 1, 546.

${ }^{5}$ Brozovic, B, et al, British Medical fournal, 1971, 1, 695.

(Accepted 22 fanuary 1979)

St Bartholomew's Hospital, London EC1A 7BE

A M COTTERILL, medical student

J N FLATHER, medical student

W R CATTELL, MD, FRCP, consultant physician, department of nephrology M D BARNETT, BSC, research assistant, department of haematology

L R I BAKER, MD, FRCP, consultant physician, department of nephrology

\section{A case of Dettol addiction}

Joubert et al ${ }^{1}$ described a case of severe poisoning from ingestion of Dettol. We report a case of Dettol addiction, which we believe to be the first such case to be recorded.

\section{Case report}

A 56-year-old cachectic woman was admitted to hospital with anorexia, weight loss, and abdominal distension for three months. There were no other gastrointestinal symptoms. Her medical history contained nothing of note; she worked as a cook and had been divorced for 10 years. She was emaciated with gross ascites and oedema of the legs. A large mass was present in the right iliac fossa and the liver was slightly enlarged. There was no abnormality in the cardiovascular or central nervous system but she had pneumonic changes in both lungs. Alkaline phosphatase activity was $180 \mathrm{IU} / \mathrm{l}$ and $\gamma$-glutamyltransferase activity $84 \mathrm{IU} / \mathrm{l}$, and isoenzymes were of liver origin; other biochemical values were within normal limits, as was a full blood count. There was no abnormality of renal function and no evidence of sexually transmitted disease.

While an inpatient she was observed drinking undiluted Dettol $(4 \cdot 8 \%$ chloroxylenol in isopropyl alcohol) and also to use Dettol-soaked pessaries. Three bottles of Dettol $(500 \mathrm{ml})$ were found in her locker. She admitted to drinking Dettol for at least 10 years to "purify" herself but denied ever drinking more than half a bottle a day. Her 25 -year-old son stated that she had been well until seven or eight years before, when she developed an overwhelming fear of acquiring syphilis; this occurred after her marital disharmony and coincided with the onset of Dettol abuse, which was limited initially to small amounts only and increased gradually. Over the year before admission she had become confused and disorientated. While in hospital she underwent psychiatric assessment and a schizophrenic illness was diagnosed.

\section{Comment}

We can find no other case of long-term Dettol ingestion leading to probable addiction. Dettol contains some isopropyl alcohol in addition to chloroxylenol, and this is the next most common alcohol after ethyl and methyl to which addiction occurs. Ingestion of isopropyl alcohol occurred in two-thirds of the non-ethyl-alcohol addicts described by Mendelson et al. ${ }^{2}$ The motivation in our case was 